\title{
Variantes del
}

ensayo en revistas

digitales de

Argentina.

Coyunturas,

escrituras,

experiencias

Diego Germán Vigna

Recebido em: 23 de setembro de 2018

Aceito em: 22 de outubro de 2018

Diego Vigna es Doctor en Estudios Sociales de América Latina por la Universidad Nacional de Córdoba, Argentina. Es Investigador del Centro de Investigaciones y Estudios sobre Cultura y Sociedad (CIECSCONICET) y docente del Centro de Estudios Avanzados (FCS-UNC). Su último libro es Los Desvalidos. Fotografías, textos periodísticos y ficciones de Daniel Moyano (CRLAArchivos, 2017).

Contacto: diegovisna@gmail.com Argentina 


\section{PALABRAS CLAVE:}

Soporte digital; Ensayos de escritores; Revistas culturales y literarias; campo literario argentino.
KEYWORDS: Digital media;

Writers' essays; Cultural and literary magazines; Argentine literary field.
Resumen: Este artículo aborda formas textuales que son consideradas como ensayísticas y que se distinguen, en su condición de publicaciones digitales, por objetivos, indagaciones y estéticas dispares, lo que obliga a revisar la tradición del ensayo construida sobre la cultura impresa. El análisis no parte de los textos, ni de sus autores ni de los temas que abordan, aunque desemboca en estos aspectos. La mirada surge de la reflexión sobre el soporte digital y los formatos de publicación web, partiendo del reconocimiento específico de la revista cultural y literaria como el "artefacto mediador" que en Argentina dio densidad y dinamismo a la producción ensayística. El objetivo del trabajo es mostrar registros ensayísticos firmados por escritores que se publican en revistas digitales y que dan cuenta del trabajo actual de instituciones y formaciones en el campo literario nacional.

Abstract: This article focuses on textual forms, which are considered as essays and distinguished, in their condition of digital publications, by dissimilar objectives, inquiries and aesthetics. This differences forces us to revise the tradition of the essay, constructed around printed culture. The present analysis does not originate from the texts, nor from their authors, neither from the topics that they address, although it ends up on these aspects. The approach starts from the consideration on digital media and web publication formats, starting from the specific recognition gave to the cultural and literary magazine. These are considered as mediating artifact which have given dynamism to the essay production in Argentina. The objective of this work is to show essays signed by writers that are published in digital cultural and literary magazines, accounting for the current work of institutions, groups and agents from the national literary field. 


\section{INTRODUCCIÓN}

Misteriosas formas las del ensayo en tanto género literario, registro interpretativo o impulso escritural, que con tantos antecedentes mantiene su condición movediza frente al repertorio crítico que aún intenta definirlo. Y renovado misterio el de las revistas culturales dentro del campo literario argentino, que con una frondosa historia de producción desarrollada durante el siglo XX ha desplegado, en lo que va del nuevo siglo, un nuevo campo de acción en el ambiente digital.

Aquí pretendo recuperar algunas formas textuales que son nominadas o sugeridas como ensayísticas y que se distinguen, en su condición digital, por objetivos, indagaciones y estéticas dispares, obligando a revisar la tradición construida sobre la cultura impresa. Mi punto de vista no parte de los textos, ni de los escritores que los firman ni los temas que abordan, aunque luego desemboque en esos aspectos. La mirada nace de la reflexión sobre los formatos de publicación, partiendo del reconocimiento de la revista cultural como el "artefacto" mediador que en Argentina dio densidad y dinamismo a la producción ensayística, tanto en su faceta literaria como interpretativa. El objetivo del trabajo es mostrar registros ensayísticos firmados por escritores, que se publican en revistas digitales de cultura y literatura, y que dan cuenta del trabajo actual de instituciones y formaciones en el campo literario nacional.

En 2007 Liliana Weimberg afirmaba que, en medio de mestizajes y sincretismos, los ensayos comenzaron a repartirse entre el ámbito editorial y académico, las revistas culturales, la prensa gráfica, y también internet. 
Mezclados con narrativa, prosa poética, teatro, ciencias sociales e incluso filosofía, esos textos que ofrecen la perspectiva de un autor sobre el mundo y que han sido protagonistas del discurso crítico en su función pública plantean desde hace décadas el desafío de analizarlos en el marco expansivo de los discursos de la comunicación mediática (Weimberg, 2007). ¿Qué se nombra como ensayo en el ecosistema de medios digitales? ¿Cómo son esas formas textuales que brotan en la Web, a manos de escritores, y que no encajan fácilmente en nichos reconocibles? ¿Cómo definir textos que coagulan en la nube, al decir de Chejfec (2015)? La búsqueda debe retrotraerse a cómo se gestaron las condiciones de producción actuales, para así indagar sobre los temas y problemáticas que se abordan en lo publicado por las revistas literarias digitales. La discusión durante el siglo pasado sobre la existencia de una literatura o pensamiento nacional, y luego regional, que conlleva a la discusión ideológica y política, parece haber dejado lugar a la discusión sobre la nueva estructura (y lógica) mediática que define la esfera pública, y a la cada vez más influyente mediación técnica, tanto en la producción literaria como intelectual. Esto lleva a la reflexión sobre los cambios en el papel del intelectual en el contexto argentino, sus campos de acción y formas de legitimar y transmitir ideas.

La distinción que propuso Weimberg (2007) sobre registros del ensayo que defienden los "fueros literarios", y otros de corte interpretativo, quedó atravesada por la naturaleza técnica de la reproducción, que es producto de un proceso socioeconómico sostenido en la oscilación a veces tramposa entre lo global y lo local, como también afirmó Moraña (2003), desde 
Variantes del ensayo en revistas digitales de Argentina. Coyunturas, escrituras, eXperiencias

hace décadas. Eso impacta en la dificultad que Weimberg encuentra en este siglo para establecer una visión de conjunto "basada en el modelo histórico y cultural que comenzó a gestarse en el siglo XIX” (2007, p.124). Las formas ensayísticas, en sus facetas digitales, han ido alejándose de las interpretaciones totalizantes heredadas, pero también han generado grados de autonomía y procesos de experimentación. Para pensar sobre "lo que se habla” en esos registros de escritores, entre la literatura, la coyuntura político-económica y el periodismo cultural, tomaré ejemplos de las revistas Anfibia, Carapachay, Transas y Atletas que creo representativos del funcionamiento heterogéneo del campo local. Proyectos con orígenes, financiamientos y objetivos distintos. Para el análisis utilizaré la figura del encuadre en sentido doble, fotográfico y empírico: un recorte que permite atender a una perspectiva de producción, y también discernir movimientos de otros proyectos observados, a la manera de una hoja de contactos que hace, de la producción de las revistas en conjunto, un relato mayor.

Beatriz Sarlo y Roxana Patiño han destacado las estrategias históricas de las revistas para construir sus discusiones y elegir temas, interlocutores y perspectivas de abordaje; las han definido como laboratorios estéticos, políticos y literarios. En ese sentido, la pregunta sobre cómo se han reacomodado los géneros dentro de las revistas ayuda a pintar la época, y a observar cómo se construyen estrategias de intervención e interlocutores. 


\section{FORMAS HÍBRIDAS, PRIMERA PERSONA Y CONTEXTOS DE PRODUICCIÓN: UN REPASO}

Varios autores han destacado la esencia híbrida, flexible y transversal del ensayo. Ana Cecilia Olmos desde la relación entre ensayo y escritura, al igual que Sarlo y Saítta, que sumaron, como Patiño y Weimberg, la relación ensayo-arte-sociedad a través de la crítica latinoamericana, sobre todo en revistas. Para Olmos, el ensayo ha podido postularse como una escritura que, por un lado, puede objetivar un determinado saber acerca del mundo, y por otro dar lugar al conocimiento de sí: una "escritura autoreflexiva que activa el gesto crítico de la sospecha” (2009, p.4), o como rescata Saítta de Nicolás Rosa, un intento de "explicar el propio estupor" ante experiencias de ruptura (2004). Para Weimberg, el ensayo ha sido puente permanente entre la escritura del yo y la interpretación del mundo, entre la situación concreta del autor y la inscripción de su experiencia en un horizonte de sentido más amplio (2007). Ese doble movimiento, compartido por todas las posiciones, da cuenta de una sospecha inherente que no sólo es sobre lo que rodea, sino sobre la propia constitución subjetiva que, siguiendo la línea barthesiana, se construiría en la misma instancia de enunciación, como dice Olmos (2009). Esta consideración versátil de la escritura ensayística como herramienta creativa que opera por dentro y por fuera es la base que permite abordar semejante disparidad de textos a lo largo de las épocas.

Recupero entonces la distinción que propuso Weimberg: la que responde a la reflexión sobre la escritura, la literatura y el propio hacer como una moral de la forma, y la que responde a una intención más amplia 
e interpretativa, compuesta de intervenciones en la esfera pública que proponen miradas sobre la realidad, local o global. Weimberg invierte el sintagma para esta última: una forma de la moral (2007). Esta última amplía la posibilidad de abordar distintas expresiones textuales. Lejos de la especialización, Weimberg arriesga una definición amplia del ensayo de corte interpretativo como "prosa no ficcional destinada a tratar todo tema como problema”, a ofrecer nuevos puntos de vista, a reinterpretar distintas modalidades del mundo cruzando fronteras o mezclando lenguajes (2007, p.117). Desde esta perspectiva se puede pensar al ensayo, en todas sus variantes, como una estrategia textual de intervención pública capaz de construir saberes provisorios y tentativos porque, como describe Saítta, no requiere verificación ni comprobación científica (2004, p.107), aunque como señalaran Weimberg, Sarlo y Patiño hoy sea una forma asimilada por varias disciplinas de las humanidades y ciencias sociales.

Lo cierto es que a partir de esa hibridez constitutiva, estas constataciones al menos intentan deslindar un terreno. Casi paradójicamente, en medio de ese intento Weimberg y Saítta coinciden en recuperar dos elementos fundamentales de abordaje que en principio se ubican por fuera del texto: la firma y la responsabilidad. Para Weimberg (2007), quizás la única frontera que separe al ensayo de otras manifestaciones similares sea el respaldo de un nombre. Una firma que se convierta en ejercicio de responsabilidad. La firma de un ensayo generaría ese tránsito de la perspectiva propia al mundo interpretado y viceversa (2007, p.118). Para Saítta, esta apelación al nombre propio consolida esa doble faz: la voz en singular que habla desde 
dentro ofrece una interpretación del mundo a la vez que permite analizar esa propia mirada; y la faz objetiva, traccionada por la firma, asume un compromiso con el lector (2004, p.108).

Esto sirve para introducir los cambios de época en los contextos de producción. Weimberg nombra la evolución del ensayo como un paso de tierra firme a "género sin orillas", que hasta mediados del siglo XX era un lugar clave de articulación entre el campo literario y el campo intelectual, con el ensayista como figura representativa basada en sus temas, su relación con el público y con el mundo del libro (2007). La condición "sin orillas" se la atribuye al cambio de épocas y contextos, que impactó en nuevas demandas temáticas y formales, nuevas variantes de autoría, de lectura y edición. Transformaciones, dice Weimberg, en la familia de la prosa de ideas (2007). De su categorización de esas transformaciones rescato tres aspectos. Primero, la dimensión espacio temporal, y las nuevas formas de traducir la comprensión y la narración de la experiencia, que Weimberg reconoce en abordajes vinculados a la autobiografía, la memoria y el testimonio. Segundo, el paso de mostrar a decir: según dice, el ensayo latinoamericano cumplió durante muchos años la función de mostrar y señalar problemas de contexto; indicar y diagnosticar problemas de una realidad social y cultural a transformar (2007, p.112). Eso fue cambiando a manos de la expansión de las ciencias sociales, que se nutrieron del ensayo, así como las variaciones en la idea del sujeto-autor y su sometimiento a crítica, que decantó en nuevas fronteras entre géneros y formas enunciativas 
con los escritores como protagonistas $(2007)^{1}$. Por último, los cambios en la relación de la prosa de ideas con su difusión pública. Weimberg destaca algo cada vez más evidente en las últimas dos décadas: el cambio de las formas de debate y divulgación, el cambio en los ritmos de lectura y escucha, y la expansión de otros territorios como el virtual, donde muchas veces "lo social se vive como individual y la experiencia privada se vive como parte de una red indeterminada" (Weimberg, 2007, p.113). Si el ensayo formaba parte de un espacio público de discusión, una experiencia intelectual y estética compartida, hoy su efervescencia queda restringida a la esfera mediática, y desde allí a la cotidianeidad de las redes.

Eso lleva a lo que Weimberg denominó "texto cerrado/fenómeno abierto", tensión producida por el surgimiento de la hipertextualidad y la nueva exploración de límites para el texto (2007, p.114). El ensayo debió adaptarse a la irrupción tecnológica, la complementariedad de soportes que alteró los canales tradicionales de circulación, las formas de producción y recepción. Los procesos editoriales no han quedado exentos al cambio, y la reflexión sobre esos procesos se vuelve tan fragmentaria como los textos. Este es un elemento clave para distinguir escrituras que nacen de procesos

1 Olmos (2009) estudió la profusa aparición de narradores, a partir de los 90, desarrollando una producción ensayística en paralelo a la literaria, en general por encargo, que llevó a alternar y a veces fundir el registro ensayístico con el ficcional como modo de expansión crítica sobre la propia escritura (ver Piglia, Saer, Tununa Mercado). Alberto Giordano lo explicó como una zona de desplazamiento de la reflexión teórica e intelectual de estos escritores, que rehúye la discursividad de la crítica literaria e intenta operar una literaturización del saber que contamine y difumine desde la experiencia literaria y estética las certezas de la crítica académica (2005). 
dislocados respecto de las huellas de representatividad asentadas por la tradición impresa.

El repaso de cambios es extensible a la figura del intelectual. Tanto Weimberg como Sarlo, Patiño, Moraña y Saítta coinciden en señalar la corrosión del modelo de intelectual heredado, a manos de, según dice Sarlo (1997), la lógica de la esfera pública mediática, que ya no necesita mediadores culturales porque (agrego yo, pensando en Ludmer [2006]) los medios transmutan la realidad y los hechos a su pura representación ${ }^{2}$. Es verificable el argumento de que dicha esfera privilegia una "retórica de los particularismos" que deja fuera la intervención intelectual ${ }^{3}$, según Patiño (2017): problematizaciones de corto alcance, sumidas a las agendas periodísticas que dominan claramente los espacios de opinión y análisis. Los intelectuales han pasado a hacerse visibles sólo cuando pueden oficiar de expertos o técnicos adecuados a la lógica comunicacional (la misma Sarlo es un ejemplo actual en Argentina). Por esas instancias, para Sarlo han desaparecido las voces universales que toman partido, porque no están dadas las condiciones de enunciabilidad que las legitimen (1997). Esto es importante para comprender las condiciones de producción y recepción

2 Para Ludmer, eso "cotidiano" que transcurre en los medios no es la realidad histórica, referencial y verosímil del pensamiento realista y de su historia política y social, sino una realidad producida y construida por los medios, las tecnologías y las ciencias (2006).

3 Moraña también se refirió a esto: "El intelectual se enfrenta hoy al descentramiento y la desauratización de la cultura letrada, y al predominio instrumental que busca transformar la función intelectual y los mensajes y códigos en que ésta se apoya en dispositivos que transmiten un saber especializado y negociable en el mercado vasto de los bienes simbólicos" (2003, p.72). 
de lo que hoy puede nombrarse como ensayo: un "lugar" de producción que ya no es un "lugar universal" reconocido para el discurso intelectual, a caballo de una crisis de representación que es transversal a la política y la estructura mediática.

Para Olmos es constitutiva del ensayo una enunciación fragmentaria, ausente de certezas categóricas, oscilante. Un espacio que evidencia el gesto crítico de indagación inherente a toda práctica literaria (2009, p.4). Esta caracterización que mira desde la escritura trasciende los soportes, aunque con una salvedad. El impulso de propiciar gestos críticos depende en buena parte de las velocidades de producción, circulación y recepción. Y eso se ha trastocado con la irrupción digital.

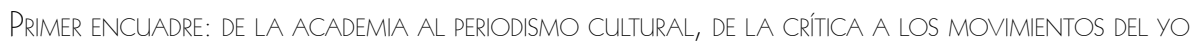

Las revistas digitales surgieron en Argentina a la par de los blogs personales, en un movimiento posterior a la crisis estructural de 2001 que consolidó un campo editorial atravesado por la concentración de sellos importantes y la atomización de sellos incipientes o pequeños. Con la devaluación de la moneda, muchos proyectos colectivos se atomizaron en pequeńas editoriales impresas que luego, por los costos reducidos, pasaron a experimentar con el mundo digital (Echeverría, 2009). La posibilidad de administrar un blog también impulsó en los autores nuevas experiencias de escritura, edición y difusión sin intermediarios (Vigna, 2014). Pero al margen de los blogs, la tendencia a la atomización de proyectos culturales y literarios puede rastrearse en Argentina desde la década de 
1990 en adelante. La crisis propició formas alternativas de circulación y de promoción de autores y obras, sobre todo jóvenes que utilizaron como trampolín los cambios en los hábitos de lectura, más fragmentarios. Las revistas digitales, surgidas de la gestión tanto de formaciones aisladas como de autores involucrados con la academia (las dos primeras revistas digitales con pretensiones, No retornable (2005) y El interpretador (2003), nacieron de iniciativas de estudiantes y profesores de la Facultad de Letras de la Universidad de Buenos Aires), dinamizaron la producción y la recepción conformando nuevos públicos y visibilizando nuevas firmas, mientras continuaban la tradición de plataformas de debate cultural y artístico.

La multiplicación de publicaciones digitales llevó a que las revistas hoy apelen casi siempre al formato blog para definir identidades y políticas de contenidos. Esto reformuló la tradición de estudios de revistas impresas que, como afirmó Artundo (2010), permite en su faceta material distinguir características que hablan de las decisiones de cada proyecto. En el marco digital, es necesario ubicar en lugar de la materialidad a la visualidad como elemento central en torno al diseńo. Casi todas las revistas son revistas-blogs o mixtas (Vigna, 2015), en las que plantillas y presentación de contenidos dan cuenta de sus objetivos de publicación y tiempos sugeridos a los lectores. Una revista-blog (Anfibia, Transas, Atletas $)^{4}$ ofrece sus publicaciones sin apelar a un número o dossier; actualiza contenidos sin una periodicidad definida y suele ofrecerlos modularmente respetando

4 Ver, por ejemplo, Atletas: http://atletasrevista.com/ 
una cronología inversa, con las últimas entregas en la parte superior. Esa presentación modular de contenidos genera zonas donde encontrar los textos, con secciones generalmente definidas por una organización semántica (etiquetas). Una revista mixta, por su parte, responde a los mismos rasgos pero anuncia actualizaciones de contenidos como "nuevos números", que se ordenan en el mismo sentido pero detallando una secuencia numérica (Bazar Americano o Carapachay) 5 .

Pero ¿qué formas adopta la escritura argumental, la reflexión estética, la narrativa no ficcional en estos instrumentos de mediación cultural, como los definió Moraña (2003)? Comienzo por Anfibia y Transas. La primera se presenta desde la investigación periodística ${ }^{6}$ pero también contempla el "funcionamiento del yo" y la inscripción de la experiencia traducida a la digitalidad, mientras que Transas busca intervenir el campo de debate de la cultura latinoamericana ${ }^{7}$. Sus pertenencias institucionales hablan del clima de época en el campo de las publicaciones periódicas: fueron creadas y dependen de la Universidad Nacional de San Martín (Buenos Aires),

5 Carapachay: https://revistacarapachay.com/. Bazar Americano: http://www.bazaramericano.com/

6 Se presenta como "revista digital de crónicas, ensayos y relatos de no ficción que trabaja con el rigor de la investigación periodística y las herramientas de la literatura". Fue creada en 2012. En su "imagen pública", la material textual y la visual balancean el impacto gráfico, entre la sensibilidad estética y la potencia documental.

7 Transas es mantenida por estudiantes de posgrado de la UnSam. Según se explica en la revista, los estudiantes "transan" en el sentido de vincularse con profesores, escritores, periodistas, historiadores y lectores para transponer los límites de la academia y buscar nuevas formas de expresión y debate en torno a la cultura. Esa transposición se explicita en forma de crónicas, ensayos, entrevistas, reseńas. 
pero apelan a la conformación de modos de recepción y reproducción que excedan al discurso académico y científico especializado, buscando operar en la zona de contacto entre políticas culturales hegemónicas y proyectos alternativos ${ }^{8}$, como afirma Moraña (2003, p.68).

En Anfibia denominan "ensayos" a un abanico diverso de textos, que sin embargo caben dentro de una sección así denominada, a diferencia de Transas que los agrupa dentro de una sección llamada "Discusión". La mayoría de los textos que Anfibia publica como ensayos responden a los tiempos de la agenda periodística en Argentina, atendiendo a los hechos de mayor repercusión que invaden los discursos de los grandes medios de prensa (en el último año hubo varios ejes: la visita papal a Sudamérica, casos de gatillo fácil en Argentina, la ley de Interrupción Voluntaria del Embarazo). Anfibia representa a un sector muy dinámico de la intervención cultural que considera a la actualidad como un valor y que llevó a la asimilación, por parte de distintas manifestaciones intelectuales, del discurso periodístico y la crítica cultural, sobre todo en las últimas décadas. Valor, la actualidad, que es razón de ser de los formatos digitales. La relación entre ciertos registros ensayísticos y el periodismo es una de las facetas más recurrentes en los medios digitales; dentro de lo que Weimberg denominó ensayo de interpretación distingo un bloque de textos que trabajan entre la superficie de la información y los estratos subyacentes del análisis social, político y mediático, que podría llamar registros ensayisticos de coyuntura (puede verse

8 Otro ejemplo es Luthor, editada por docentes de Filosofía y Letras de la Universidad de Buenos Aires. 
en Anfibia, Panamá, Paco ${ }^{9}$, etc.). Lejos está, esta zona de producción, de los fueros literarios característicos del ensayo, que se han amoldado con mayor prudencia a las dinámicas de publicación digitales. El discurso periodístico lo hizo con agilidad porque junto al valor de lo actual, la noción de velocidad se constituye como el vector, paradojalmente, que propicia formas de acceso, lectura e interpretación de las ideas.

Buena parte de los ensayos de Anfibia se acerca a lo que el discurso periodístico llama "artículos en profundidad", aun cuando los temas son literarios y están firmados por escritores. Por ejemplo, en 2018 se publicó "El gran camaleón" ${ }^{10}$, firmado por Enzo Maqueira y dedicado a la figura de Tom Wolfe en el marco de su fallecimiento. El perfil es estrictamente periodístico: lejos de un abordaje de obra, se ofrece como un obituario. No hay primera persona, ni premisas estructurantes, ni potencia conjetural, como en otros textos que utilizan recursos asociados a la escritura literaria, como el desarrollo de escenas, diálogos directos, construcción de personajes. Otro ejemplo es el texto de claro corte ensayístico que leyó Claudia Piñeiro ${ }^{11}$ en la inauguración de la Feria del Libro de Buenos Aires 2018: fue publicado como ensayo pero respeta las marcas de su exposición oral.

9 http://panamarevista.com/, https://revistapaco.com/

10 Ver http://www.revistaanfibia.com/ensayo/el-gran-camaleon/

11 Ver http://www.revistaanfibia.com/ensayo/la-disidencia-estado-alerta/ 
La firma como sostén argumental e ideológico no siempre es un elemento decisivo entre los textos que se ofrecen como ensayos de coyuntura, lo que suscribe el panorama descrito sobre las mutaciones de la intelectualidad y su poder simbólico restringido: se corre la relevancia de la mirada autorizada hacia el dato y la empiria. Pero también es cierto que la potencia enunciativa, al menos en el caso de Anfibia y de otras revistas que parten del periodismo para llegar a la crítica cultural, parece ser reemplazada por otros lenguajes que sí estructuran el ambiente hipermedial, como las fotografías, las ilustraciones y los emojis y gifs, recursos expresivos corrientes en el seno de la cultura digital. En Anfibia se impuso la fusión de registros que buscan profundizar en problemáticas específicas con una insistente presencia de enlaces hipertextuales, que deriva sentidos hacia otros textos (nodos) de la web. ¿Cómo puede pensarse, en este sentido, la evolución de variantes del ensayo sumergidas en la deriva del hipertexto; prosas de corte interpretativo que son pensadas desde su origen para ser leídas entre pantallas y redes? ¿Cuánto aporta la hipertextualidad a una línea argumentativa?

Cito estos ejemplos para reforzar una primera evidencia: dentro de la heterogeneidad de escrituras en la web, el registro ensayístico de coyuntura exige un repensar del género para comprender las rutinas actuales de lectura y navegación. ¿Qué hace, hoy, funcionar a los distintos tipos de ensayo, y qué los ata a su "pasado"? Para complejizar aún más la tensión entre problemas, reflexiones y velocidades, las variantes en las que los fueros literarios toman relieve también están presentes en revistas atentas a la 
coyuntura. Y en esos casos sí toma protagonismo la firma como elemento estructurante del género.

En el marco de los debates por la lucha feminista, Anfibia publicó en 2018 "La menesunda del feminismo" 12 , firmado por María Moreno. Es otro texto a cargo de una figura relacionada con la escritura de ficción, y remite a una muestra curada por la misma autora. La enunciación en primera persona replica el estilo narrativo de Moreno: una suerte de incontinencia verbal que a veces rompe la sintaxis para avanzar, desde una "escritura libre", sobre el recuerdo de personas, personajes, objetos relacionados con su muestra que abarca la historia del feminismo en Argentina. Podría pensarse más cerca de la promoción que de la reflexión, sobre todo porque las marcas textuales así lo indican: es un texto por encargo. Pero en medio de esas condiciones de producción, "La menesunda" permite observar cómo opera una escritura ensayística en formato web. La asociación libre, trasladada a la sintaxis, recupera la esencia del pensamiento íntimo en estado de exposición

12 Ver http://www.revistaanfibia.com/ensayo/la-menesunda-del-feminismo/ 


\section{Anfibia 口ᄆ}

Ilustración de portada: Tiempo Argentino - La Mujer

Células Madre vuelve a mostrar mi vertiente Marta Minujin, tan tristemente reprimida a lo largo de mi vida periodistica en la que la única performance posible parece pensada para dos dedos, los mismos considerados culpables en los antiguos diagnósticos médicos por masturbación, de uña un poco mocha y precozmente artrósica por el uso de los apuntes en block. Es que mi vocación artística fue rápidamente desengañada. Carlos Gorriarena estalló de risa ante mis maternidades beatificas dibujadas con la estética de una propaganda de leche en polvo, Manuel Puig casi vomitó ante un cuadro que representaba niños pobres copiados de Berni y donde todos tenían los ojos como los de los peces telescopios, mis posters psicodélicos, hechos con pintura fluorescente, tenían la rigidez de la espada de Darh Vader. Es verdad que en las jornadas Mansilla que organicé en el centro Cultural Ricardo Rojas, hice preparar el puchero que se servia en Una excursión a los indios ranqueles, que Sebastián Freire hizo lo posible Pero, ¿qué es Células Madre? Acá en Anfibia todos saben que odio dar datos, lo considero una interrupción de mi asociación libre. Menos mal que escribí un espich para la muestra. Es éste:

Células madre (La prensa feminista en los primeros años de la democracia)

El 8 de marzo de 1984 una morocha argentina subía con tacos altos, cartera bolsa y chemisier claro, a la Plaza de los dos Congresos. En su mano derecha llevaba una pancarta que decía "No a la maternidad, si al placer". Era la militante feminista

Capturas de imasen: fragmentos de "La menesunda...", de María Moreno. Publicado el 28/06/2018.

En Transas, dedicada a "poner en escena lecturas y relatos sobre las letras y artes de América Latina”, también se encuentra esa presencia renovada del ensayo de escritor. Silvia Molloy cedió a la revista en 2017 el texto "Epílogo: The Buenos Aires affair"13 donde presenta una primera persona atenta a las sensaciones de sus idas y retornos a Buenos Aires. La narración se entremezcla con lo argumental; la palabra reflexiva nace del recuerdo y contrasta con el presente. Molloy experimenta con la memoria de sus

13 Ver http://www.revistatransas.com/2017/11/03/epilogo-the-buenos-aires-affair/ 
decisiones frente a la escritura de sus novelas y a las vivencias de sus lugares; pinta su relación esquiva con los sitios que habitó y expone, cerca del tipo de ensayo que describe Olmos ("una palabra suplementaria que, despojada de las instancias mediadoras del narrador o del personaje, le permite interrogarse acerca de las motivaciones que incitan su práctica” [2009, p.4]), una mirada sobre el exilio voluntario, oscilante entre la distancia que se escribe (se ficcionaliza) y la cercanía que se vive (acto frustrado de "volver para recordar más cerca”, que rompe el recuerdo y por tanto la ficción sobre el lugar propio). Este tipo de textos destaca, en algunas revistas, el lugar de la percepción como modo de construir el mundo propio. Una constatación de la función de pervivencia y memoria que cumple la ficción, condicionada por su contraste con el mundo material.

En ese sentido puede pensarse también "Con su sangre escrita"14, publicado en 2016 y firmado por Tununa Mercado, sobre Sor Juana Inés de la Cruz. Se lo presenta en "Discusión", aunque fue elaborado como ponencia, luego replicada en la revista. El tema encaja con el perfil de Transas: se trata de un relato en primera sobre la poeta insignia del latinoamericanismo, y de la posición femenina en la literatura. Pero huele anacrónico en la mejor interpretación del término: lejos está, como la obra de Mercado, del valor exaltado del debate coyuntural, como también de una forma genérica definida (las prosas y narraciones de Mercado actúan por fuera de los géneros reconocibles, más allá de su carácter ficcional).

14 Ver http://www.revistatransas.com/2016/09/22/con-su-sangre-escrita/ 


\section{En este caso, lo que propicia el soporte es la incorporación de imágenes que refuerzan la percepción intimista, aunque también neutraliza el juego mimético que sirve para la construcción poética.}

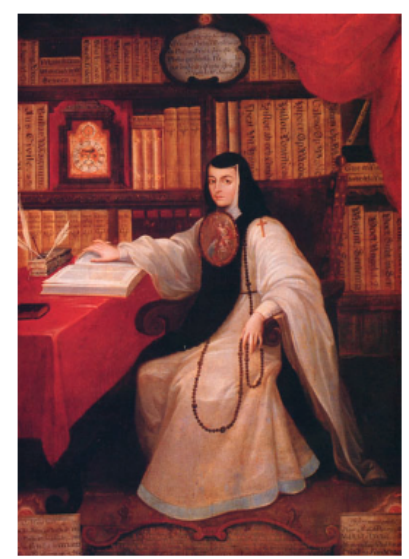

Yo observo uno de sus retratos: Una niña a los 15 años, bella, las cejas perfectas, los labios no hurtados a la mirada ajena, el pelo negro, raya al medio, adornado con pequeñas flores rojas, medallón en el escote, senos insinuados, vestido de seda bordada y rebozo, con un libro en la mano derecha, en la izquierda el gesto que explaya la oratoria expositiva...

He llegado a Nepantla. De la casa donde nació sólo queda parte de la cocina. Allí no llegó a cocinar la monja. Hoy es un sitio de culto fragmentado. Como es fragmentado mi acercamiento a una obra cuyo labrado es misterioso, pero sin embargo aprehensible al tacto, a veces como una pedrería, otras como una estola bordada con hilos de oro, una partitura cuya música transgrede la tersura plana para romper y alterar los lugares de la frase en busca de un ritmo o una rima. Juegos de la lengua, desafío constructivo y, en la obra mundana, un canto, una danza, el ingenio para "hacer un tema", una pieza de música.

Escribí estas páginas pensando en Graciela Hierro, en su memoria. Filósofa, feminista, sorjuanista. En el muro de su casa de Tepoxtlán, junto a la puerta de entrada hay una cerámica poblana que dice "Primero sueño", y da nombre a su casa. Mi casa de la Cumbre lleva el mismo nombre. Casas gemelas, cerámicas gemelas, admiraciones gemelas. Primero sueño. ¿Y después?

\section{POR REVISTA-TRANSAS}

ETIQUETAS: El SILENCIO INTERRUMPIDO, GénERO, SOR JUANA

Capturas de imagen: Fragmentos de "Con su sangre escrita", de Tununa Mercado. Publicado el 22/09/2016. 
Los ejemplos de Moreno y Mercado sirven para marcar una alternativa a las velocidades impuestas por los medios digitales. En medio de la incesante publicación de registros de coyuntura, y aunque no ocupe el centro de la construcción de sentido, el yo no deja de filtrarse en los textos argumentales para traducir una mirada sensible sobre el entorno, por fuera de la ansiedad del dato. El yo se cuela marginalmente entre los intentos de analizar la coyuntura para discutirla en tanto superficie de significaciones. Muchas revistas trabajan para preservar al ensayo de la "ansiedad interactiva", y de las escrituras sin editor ${ }^{15}$ que colman las redes sociales digitales, cada vez más dominantes en el ecosistema digital: escrituras yoicas que nacen para la simultaneidad en la inscripción de voces, como lo prueban Facebook o Twitter.

Segundo encuadre: de la política a la poética. SensibILIdAdes en el anÁlisis de eSCRITURAS Y ENTORNOS

El posicionamiento del ensayo desde las revistas como modo de instalar espacios de reflexión diferenciados de la academia no depende de lo digital, aunque encontró en su lógica una alternativa para refractar, como dice Patiño (2017, p.51), el imperio del paper, hoy en su punto más álgido. En el campo intelectual argentino poskirchnerista (que habla más de un contexto histórico de producción que de un posicionamiento ideológico), muchas revistas buscan alternativas a los discursos científico y académico

15 En las revistas sobrevive en la web la figura del editor, que las redes sociales digitales dicen anular para que todo usuario sea productor y administrador de sus intervenciones. 
autonomizándose en sentido político, crítico y estético, aunque la relación entre formaciones culturales e instituciones de investigación se haya fortalecido notablemente. Quizás esto se produzca por la pérdida de peso e intervención pública que vienen sufriendo estas publicaciones, como afirma Hernaiz (2012). El proceso que señaló Patiño (2017) sigue agudizándose; la política ya no opera como elemento de censura u obturación de los discursos, por lo que éstos ya no se interesan por taponar sino más bien por hacerse visibles en el seno de condiciones de recepción muy distintas. Lo mismo señala Weimberg (2007) con lo que llamó "rupturas críticas", que no nacen de la convivencia de soportes ni de las mutaciones en el campo editorial, sino por la desarticulación de lo que llama un "espacio ideológico" reconocible. Quienes hoy buscan recuperar el poder del registro ensayístico por fuera de la coyuntura lo hacen bajo la premisa de auscultar la enorme producción intelectual y artística que la digitalidad ayuda a difundir, fragmentariamente, como si fuera una entidad salvadora. Pero también lo hacen para analizar la cada vez más problemática relación entre la cultura y la lógica de consumo y reemplazo que degrada las condiciones materiales de producción.

Tomo algunos ensayos de Carapachay y Atletas, revistas muy distintas, para dar cuenta de las variantes de registros que operan lejos de las agendas periodísticas y del consumo de la cultura ambiente (Boczkowski y Mitchelstein, 2017).

Carapachay nació en 2015 a partir de una proyecto anterior ligado estrechamente al ensayo: En ciernes epistolarias. Esa revista, impresa, 
Variantes del ensayo en revistas digitales de Argentina. Coyunturas, escrituras, experiencias

se componía enteramente por cartas, recuperando la relación entre el registro epistolar y la potencia argumental que otros autores reprodujeron (Lukács, por caso, con su famoso "Sobre la esencia y la forma del ensayo" [2016]). Carapachay nació digital porque sus creadores no podían afrontar los costos de impresión, además de que pretendían dar más lugar a las imágenes (Guiñazú, 2018). Es por esto que los responsables no definen a la publicación por su formato sino por su contenido, donde el ensayo está determinado por temática (mayormente vinculadas a la política y la identidad) y no por parámetros formales. El ensayo es, para los editores, un intento o un experimento, sin que por ello se relativice su condición. Carapachay publica textos que se enmarquen dentro del gran legado argentino de los ensayos literarios e interpretativos (de Sarmiento a Martínez Estrada y desde Hernández Arregui a Horacio González, pasando por Scalabrini Ortiz y Borges).

El primer editorial de la revista propone rescatar escrituras y autores que reflexionen sobre la problemática nacional. Abordaje que, en la sección "Ensayos", se traduce en una consigna que propone a los accidentes fluviales o los cursos de agua como tema, prisma, metáfora o zona de anclaje perceptivo ${ }^{16}$. Los textos son heterogéneos: del singular en primera al plural, algunos incluso son mencionados como prólogos, extractos de libros o ponencias. El caso de Hernán Ronsino, por ejemplo, es significativo porque propone una fusión de elementos narrativos con la reflexión sobre

16 Un ejemplo representativo: "De la plata y el Paraná", de Elvio Gandolfo. Ver https:// revistacarapachay.com/2016/08/12/de-la-plata-y-el-parana-por-elvio-e-gandolfo/ 
contextos históricos, en una línea coherente con su producción ficcional ${ }^{17}$. Ronsino rescata elementos convencionales del ensayo literario con una voz concisa y reflexiva, sin por eso representar una posición conservadora, ni estética ni teórica: varios espacios en la web han reproducido este perfil, como el blog de Sergio Chejfec (Parábola anterior) durante la primera década del siglo. Ronsino parece ocuparse sólo de literatura, como en "La casa y el violín" o "La invención del otro río"18, pero su escritura se vuelve excusa para mostrar el tránsito de la lectura (la experiencia propia) a la ficción y luego al análisis social. Para esto evoca obras, entornos específicos (el territorio ribereño) y cadencias a partir de autores como Saer, Lugones o Conti.

Otros ejemplos refuerzan estas variantes escriturales de acercamiento al territorio. "Sobre el riachuelo"19, de Leonardo Sabatella, propone un verdadero ensayo descriptivo e interpretativo sobre el Riachuelo porteño, cuyo ritmo es guiado por la búsqueda de nombrar una y otra vez los vínculos entre la urbe en sus márgenes, sus habitantes y el paisaje. El Riachuelo es, en este caso, signo de la desidia política a través de su contaminación legendaria, como también receptáculo de muerte donde los responsables del terrorismo de Estado arrojaban cuerpos de militantes asesinados. Pero el texto se impone como una descripción sistemática que busca estrechar

17 Consultar sus novelas La descomposición (2007), o Glaxo (2009).

18 Ver https://revistacarapachay.com/2015/10/01/la-casa-y-el-violin-por-hernan-ronsino/ y https://revistacarapachay.com/2015/05/25/ronsino-la-invencion-del-otro-rio/

19 https://revistacarapachay.com/2018/06/04/2031/ 
Variantes del ensayo en revistas digitales de Argentina. Coyunturas, escrituras, experiencias

lazos entre lenguaje y entorno, configurando un paisaje tan plástico como arquitectónico.

\begin{abstract}
No hay un solo Riachuelo. No es que esté en cambio constante, sino que en el río coexisten transiciones y puntos inmóviles, naturaleza y urbanización. El Riachuelo, frontera sur de la ciudad, es el accidente geográfico que guarda una memoria menor, dejada de lado, casi invisible pero que ahí está materializada. El Riachuelo no es alegoría de nada, es una relación de fuerzas contradictorias y extrañas, un punto de acumulación de sedimentos históricos. Si algo caracteriza al Riachuelo es que ahí nada parece perderse, todo sobrevive de alguna manera. El agua conserva en su solución la arena del tiempo, la impureza de la memoria. El río no olvida.
\end{abstract}

Que Buenos Aires es una ciudad de espaldas al río parece un facilismo. Más bien habría que decir que es una ciudad que se amuralló contra el río. Impugnó los cursos de agua y entubó arroyos. Como si Buenos Aires quisiera desprenderse del puerto, convertirse en una ciudad deshidratada y seca. A tal punto que puede recorrerse la ciudad durante

\title{
Captura de imagen: fragmento de "Sobre el riachuelo", de Sabatella. Publicado el 04/06/2018.
}

La revista Atletas, por último, desbarata aún más cualquier intento de sistematizar estas variantes, con una sección que responde a la consigna de escribir lecturas utilizando como vehículo la primera persona. Las lecturas escritas buscan, como afirma la directora, Virginia Cosin, inscribir sensaciones e interpretaciones personales frente a una obra específica. Esto no se aleja de la tradición de ensayos literarios, pero el rasgo que rompe con los posicionamientos clásicos es que los textos pretenden construir autoría desde la experiencia sensible, sin atender a la firma. Todos los colaboradores de la revista son participantes del taller literario que dicta la misma directora. Dice Cosin: 
La revista surgió en el espacio de los talleres de escritura que coordino. La idea parte de mi propia experiencia en blogs personales. Para la gente que asiste a un taller es muy difícil insertarse en el campo profesional, publicar, colaborar en medios, etc. [...] Me pareció que una revista digital autogestionada era una buena forma de abrir el juego, salir de la endogamia del taller y dar a conocer lo que se produce ahí. [...]

En principio no encontramos otro medio que hiciera lo que nosotros queríamos hacer. Hay otras páginas o blogs que son anexos de talleres de escritura, pero creemos que Atletas es otra cosa, porque además de publicar textos de ficción también hacemos entrevistas y trabajamos un género híbrido que está entre la reseńa, la crónica y el ensayo. Si bien por ahora los colaboradores son exclusivamente participantes de los talleres que coordino, queremos expandir la convocatoria y publicar también textos de autores poco conocidos, o de gente que participe de otros talleres literarios. Nos interesa pensar en la revista como una publicación de literatura emergente, donde no sólo se pueda ver el trabajo final sino, en algunos casos, la cocina de la escritura. (Cosin, 2018)

Esas formas híbridas responden a un objetivo estético y autónomo: parten de la conmoción de la palabra en su función poética para pensar la intimidad desde esa misma poética. La lectura es el comienzo del proceso creativo; el yo como eje de la práctica con un trasfondo de cotidianeidad que acerca este tipo de textos a las formas experimentales que inauguraron los blogs de escritores (Vigna, 2014). Cosin luego expande su definición: los ensayos de Atletas pertenecerían a un género que se practica en Estados Unidos, que ella denomina ensayo personal: "está entre la investigación y la autobiografía, es un poco literatura y un poco crónica, un poco crítica y 
Variantes del ensayo en revistas digitales de Argentina. Coyunturas, escrituras, experiencias

otro poco diario íntimo. No me interesa el ensayo de tipo académico para la revista, porque para eso existen otras publicaciones. [...] Se trata de dar a conocer algo de la cocina: qué pasa por la cabeza de un lector particular cuando lee un libro x" (Cosin, 2018).

FICCIÓN ENSAYOS ENTREVISTAS RESENAS SOBRE LA REVISTA
La historia no concluye. Ingre adopta un perrito que le ofrece un niño vecino a través de la medianera, se filma
durmiendo para construir una coreografía, se enamora inesperadamente de una adolescente y se corta el pelo
ella misma. Espera la llamada de Juan. En un pueblo de Boipeba, Juan encuentra un teléfono y logra hablar con
su hermana, llega a decirle que vuelve en dos semanas pero las interferencias son muchas. Ingre no sabe si es su
inalámbrico o el abandono de su hermano mayor. Camina por la plaza de su barrio, Villa Devoto, siente
vergüenza por el placer sexual vivido con su amiga Leticia, un oprobio físico que la hace pensar en sus ancestros
yen su maternidad suspendida, pero recupera el equilibro, respira, el peso estructural se restablece sobre su
cabeza mientras mira el paso de un tren por unos segundos hasta que se desvanece.

Terminé el libro una semana antes de volver a Buenos Aires de mis vacaciones en Ilhabela, muy diferente del viaje de Juan por el norte brasileño, pero con el sabor del mar y la vegetación de la novela adheridos a la piel. Sin pensarlo demasiado, puse plantas en el baño, para compartir con ellas el agua de la ducha y recordé los momentos de mi infancia en los que quería ser bailarina. La narrativa de Gonzalo Castro se mezcló en mi vida.

Captura de imagen: final de "La trama sensible de lo cotidiano"20, firmado por Bea Greco (lueso del título se presenta como "Reseña de libro"). Publicado el 13/02/2018.

Pensamiento, escritura, digitaldad: entre la autonomía y el "Planeta secreto del yo"

El intento de caracterizar las variantes del ensayo en su faceta digital llevaría a concluir que, en medio del vértigo de los medios conectivos, con redes sociales e intervenciones de usuarios que se filtran minuto a minuto en las pantallas de ordenadores, tablets y teléfonos (un compendio

20 http://atletasrevista.com/la-trama-sensible-de-lo-cotidiano/ 
de discursos fragmentados nunca antes visto), lo que en el contexto de las revistas termina llamándose ensayo es lo que acerca la escritura a la propuesta de una linea de pensamiento. Esto no difiere de las formas precedentes; prosas no ficcionales, interpretativas, que problematizan un tema u objeto (lo que también remite a artículos en profundidad), a veces utilizando recursos narrativos, y una manifiesta carga reflexiva, atada a la idea de estar frente a escrituras que transparentan una experiencia intelectual, o un intento de verbalizar una experiencia sensible.

¿Qué aporta, entonces, la naturaleza virtual e hipermedial de los formatos web? En principio, cuatro aspectos que considero atendibles. Primero, lo que concierne a las interfaces y herramientas de edición. La preponderancia de la imagen fija y en movimiento; el "sistemas de desvíos" propio de la estructura de redes que llamamos hipertexto (la posibilidad, para el usuario, de romper la linealidad del acceso a los contenidos a través de nodos enlazados) y la multiplicidad de lenguajes conjugados, que reformularon la lectura convencional.

Junto a esa potencia, inherente a la naturaleza técnica, lo segundo: el carácter fragmentario de la escritura digital. La extensión y estructura de los textos (que puede variar, pero que tiene un límite difuso entre la economía de la atención y el tedio del scroll) hace que tienda a asociarse toda prosa con la hegemonía del artículo, aun cuando, como dice Sarlo (2001), la naturaleza del ensayo se asocie a la brevedad. Quizás esto se relacione también con lo que Weimberg llamó "nuevas formas de reflexión sobre procesos que sólo admiten hoy intuiciones lúcidas, fragmentadas, y que no 
asumen las viejas formas de representatividad en temas y discursos" (2007, p.117), lo que explicaría, en una de sus caras, los cambios en las estrategias de posicionamiento de los discursos (el intelectual deslegitimado por el mismo escenario, diría Sarlo), y la multiplicación de espacios dedicados a la novedad, la coyuntura y la información. La hegemonía del artículo en sentido digital se sostiene sobre una exaltación esquizoide de lo verificable y lo interpretable, sin ponderaciones. El imperio del dato convive con una realidad que es pura representación, ajena a eso que Saer llamó la selva espesa de lo real. En ese sentido, la fragmentariedad de la información, de lo leído, afecta, como dice Sarlo, la articulación entre pensamiento y escritura.

La otra cara de estas escrituras condicionadas por los formatos hipermediales está representada por los registros que alimentan sus fueros literarios, y que apuestan por la escritura como práctica constitutiva del sistema de desvíos que definiera Sarlo (2001, p.17) para consolidar el pensamiento crítico. Esas formas siguen apostando por los tiempos del ejercicio intelectual, las inconsistencias propias de la producción de ideas. Dan cuerpo, en ese sentido, a una autonomía revitalizada por sus implicancias cada vez más marginales respecto de la lógica comunicacional. Lejos de los flujos de información, se fortalecen. La defensa de la "moral de la forma”, que puede sonar anacrónica, quedó prácticamente a cargo de escritores que descansan de las competencias editoriales y pasan de las interpretaciones totalizantes de un entorno cada vez más inasible a la experimentación con los procesos de escritura y los tiempos del hipermedio, 
explorando recursos para la construcción del sentido. Así llego al tercer aspecto: la condición provisoria de la escritura en pantalla, más allá del formato de publicación.

Todo discurso es parte de la convivencia de soportes, con éxito o no. Pero la naturaleza en proceso de ciertas escrituras que rechazan la estabilización del pensamiento ha encontrado un terreno estimulante en la digitalidad. Algunas variantes del registro ensayístico lograron, al igual que las ficciones breves, actualizar la idea de laboratorio de escritura que supieron alimentar las revistas en papel. Hace una década, los blogs de escritores dieron cuenta de una efervescencia de pruebas y nuevas rutinas de trabajo que luego fueron neutralizadas por la presencia ubicua de redes sociales como Facebook y Twitter, que encauzaron los impulsos críticos cotidianos de los autores $^{21}$, los tanteos, la falta de certezas. Como dice Patińo, "el temblor de lo que se piensa mientras se lo escribe" (2017, p.56), renombrando la idea de Sarlo de que el ensayo es reflejo del momento en que "un pensamiento se está haciendo" (2001, p.17).

Esos impulsos, a veces sistemáticos, de contrastación de ideas e interrogantes, impertinentes para los discursos científico y académico, sobreviven en el ensayo más allá del tiempo. Quizás el aporte más reconocible de los formatos digitales sea la ampliación de la visibilidad de esa condición

21 Las redes sociales digitales canalizaron la exaltación de las escrituras yoicas, como se puede observar en los perfiles de escritores argentinos en Facebook y Twitter. El elemento disruptivo fue una gramática de uso que propone la producción y reproducción de la escritura y otros lenguajes en simultáneo a su recepción y eventual re-reproducción o intervención de los contactos. 
inacabada de todo ejercicio intelectual, a partir de una inscripción virtual y flotante. Una indagación que se sostiene en su propio vibrar; la lógica del work in progress de toda escritura que se alimenta, en estos casos, de la devolución a veces inmediata de los lectores, que desestabilizan (cada vez) toda inscripción original.

Esto lleva al aspecto más importante para el análisis de los procesos creativos, intelectuales y sociales: la exaltación de la individualidad, y cómo eso impacta cultural y políticamente en los cambios de las condiciones de producción y recepción de las manifestaciones autorales. Este trabajo da cuenta parcialmente del proceso que Weimberg nombra como la pérdida de legitimidad de un ideal de constelación colectiva (2007). Ideal que las tecnologías digitales han acechado en pos de una lógica de producción, consumo y reemplazo, transversal, en la que todo intento de búsqueda e indagación en el orden creativo y cultural compite con una estructura de sensibilidad instrumental basada en la fragmentariedad y la segmentación. El reemplazo de esa constelación de un nosotros por un "planeta secreto de un nuevo yo, el de cada escritor, el de cada experiencia" (Weimberg, 2007, p.117), sin más arraigo que la propia subjetividad, también propicia una falta de anclaje referencial, eso que Piglia nombraba como "no estar fijo en ningún lugar". El nomadismo intelectual que retoma Weimberg, en medio de estas observaciones, puede pensarse como correlato del dinamismo en los procesos de búsqueda y generación de ideas pero también como síntoma, que somete toda potencia (crítica, ideológica, creativa) al terreno restringido, a veces arbitrario, y tarde o temprano aislado, de lo individual. 


\section{REFERENCIAS BIBLIOGRÁFICAS}

Artundo, Patricia. "Reflexiones en torno a un nuevo objeto de estudio: las revistas". En: IX Congreso Argentino de Hispanistas, La Plata, Argentina, p.27-30 de abril, 2010.

Boczkowski, Pablo; Mitchelstein, Eugenia. "Smartphone, el aire que respiro". En: Revista Anfibia, Buenos Aires, 2017. Disponible en: http://www.revistaanfibia. com/ensayo/smartphone-aire-respiro/

Chejfec, Sergio. Últimas noticias de la escritura. Buenos Aires: Entropía, 2015.

Cosin, Virginia. Entrevista personal (E-mail), 19 de abril de 2018.

Echeverría, Sol. "El futuro llegó, hace rato". En: Revista No Retornable, Vol. 4, noviembre, Buenos Aires. Disponible en: http://www.no-retornable.com.ar/v4/ dossier/introduccion.html

Giordano, Alberto. Los modos del ensayo. De Borges a Piglia. Rosario: Beatriz Viterbo, 2005.

Guiñazú, Luciano. Entrevista personal (E-mail), 28 de abril de 2018.

Hernaiz, Sebastián. "Revistas literarias y lugar social de la literatura en los años noventa”. En: Revista El Interpretador, Buenos Aires, Núm. 12, abril, 2012. Disponible en: http://www.no-retornable.com.ar/v12/teatro/hernaiz.html

Ludmer, Josefina. "Literaturas posautónomas". En: Ciberletras. Revista de crítica literaria y de cultura. 2006, diciembre. Disponible en: http://www.lehman.edu/ ciberletras/v17/ludmer.htm

Lukács, György. "Sobre la esencia y forma del ensayo (carta a Leo Popper)". En Qué es el ensayo. Buenos Aires: El cuenco de plata, 2016 [1975].

Moraña, Mabel. "Revistas literarias y mediación letrada en América Latina”. En: Revista Travessias 40, Ioutra Travessia 1, 2003, p.67-72.

Olmos, Ana Cecilia. "Los límites de lo legible. Ensayo y ficción en la literatura latinoamericana”. En: Critica cultural, Vol. 4, Núm. 1 (junio), 2009, p.3-16. 
Variantes del ensayo en ReVistas digitales de Argentina. Coyunturas, escrituras, eXPeriencias

Patiño, Roxana. "El ensayismo crítico y la transnacionalización del latinoamericanismo en el Cono Sur (1990-2000)". En: Anales de Literatura Hispanoamericana, p.46, 2017, p.49-62.

Saítta, Silvia. "Modos de pensar lo social. Ensayo y sociedad en la Argentina (1930-1965)". En Federico Neiburg y Mariano Plotkin (editores), Intelectuales y expertos. La constitución del conocimiento social en la Argentina, Buenos Aires, Paidós, 2004, p.107-146.

Sarlo, Beatriz. "Del otro lado del horizonte". En: Boletín $N^{\circ}$ 9, Centro de Estudios de

Teoría y Crítica Literaria, Facultad de Humanidades y Artes, Universidad Nacional de Rosario, 2001, p.16-31.

Sarlo, Beatriz. “¿La voz universal que toma partido? Crítica y autonomía. En: Nueva Sociedad, 150 (julio-agosto), 1997.

Vigna, Diego. La década posteada. Blogs de escritores argentinos (2002-2012). Colección Gryga. Córdoba, Argentina: Alción-CEA, 2014.

Vigna, Diego. "De la tradición de revistas al mundo virtual. Aproximación a las publicaciones culturales digitales en el campo intelectual argentino de la última década”. En: Pilquen, sección Ciencias Sociales, Vol. 18, Núm. 3, 2015, p.21-35.

Weimberg, Liliana. "El ensayo latinoamericano entre la forma de la moral y la moral de la forma”. En: Cuadernos del CILHA, Año 8, Núm. 9, 2007, p.110130 . 
